\title{
Efforts to alter the trajectory of neonatal mortality in Malawi: evaluating relative effects of access to maternal care services and birth history risk factors
}

\author{
Bareng AS Nonyane ${ }^{1}$, \\ Emmanuel Chimbalanga ${ }^{2}$ \\ ${ }^{1}$ Department of International Health, \\ Johns Hopkins Bloomberg School of \\ Public Health, Baltimore, Maryland, \\ USA \\ 2 USAID's ONSE Health Activity, \\ Management Sciences for Health \\ (MSH), Lilongwe, Malawi
}

\begin{abstract}
Background The neonatal mortality rate (NMR) in Malawi has remained stagnant at around 27 per 1000 live births over the last 15 years, despite an increase in the uptake of targeted health care interventions. We used the nationally representative 2015/16 Demographic Health Survey data set to evaluate the effect of two types of maternal exposures, namely, lack of access to maternal or intra-partum care services and birth history factors, on the risk of neonatal mortality.
\end{abstract}

\begin{abstract}
Methods A causal inference approach was used to estimate a population attributable risk parameter for each exposure, adjusting for co-exposures and household, maternal and child-specific covariates. The maternal exposures evaluated were unmet family planning needs, less than 4+ antenatal care visits, lack of institutional delivery or skilled birth attendance, having prior neonatal mortality, short (8-24 months) birth interval preceding the index birth, first pregnancy, and two or more pregnancy outcomes within the preceding five years of the survey interview.

Results We included 9553 women and their most recent live birth within 3 years of the survey. The sample's overall neonatal mortality rate was 18.5 per 1000 live births. The adjusted population attributable risk for first pregnancies was 3.9/1000 $(P<0.001)$, while non-institutional deliveries and the shortest preceding birth interval (8-24 months) each had an attributable risk of $1.3 / 1000(P s=0.01)$. Having 2 or more pregnancy outcomes within the last 5 years had an attributable risk of $3 / 1000(P=0.006)$. Attending less than 4 ANC visits had, a relatively large attributable risk $(2.1 / 1,000)$, and it was not statistically significant at alpha level 0.05.
\end{abstract}

Conclusions Our analysis addresses the gap in the literature on evaluating the effect of these exposures on neonatal mortality in Malawi. It also helps inform programs and current efforts such as the Every Newborn Action 2020 Plan. Increasing access to maternal care interventions has an important role to play in changing the trajectory of neonatal mortality, and women who are at an increased risk may not be receiving adequate care. Recent studies indicate an urgent need to assess gaps in service readiness and quality of care at the antenatal and obstetric care facilities.

\section{Correspondence to:}

Bareng A S Nonyane

Department of International Health

Johns Hopkins Bloomberg School of

Public Health

615 N Wolfe Street, Room E5610

Baltimore, MD 21205

USA

bnonyan1@jhu.edu
The neonatal mortality rate (NMR) in Malawi has remained stagnant at around 27 per 1000 live births over the last 15 years [1-6]. This is despite the decrease in overall under-5 mortality rates and an increase in the uptake of targeted health care interventions such as antenatal care (ANC) visits, increased availability of obstetric and delivery services or increased uptake in facility delivery or skilled birth attendants, postnatal visits for mother and baby [3,7]. A number of challenges still remain in Malawi. Recent studies indicate that birth asphyxia, prematurity and infections account for most of the neonatal deaths [8] and 
these can be reduced with proper pre-, intra- and post-partum care. There is still low coverage of some of the interventions, for example, only $51 \%$ of mothers attended 4 or more ANC visits according to the 2015/16 Demographic and Health Survey (DHS) [3] and 44\% according to the Multiple Indicator Cluster Survey (MICS) [9]. Furthermore, even with increased access to health care, service quality and facility readiness are still inadequate [10-19].

Studies using summary data at national levels have shown that improved program efforts can lead to a reduction in preventable neonatal mortality rates in low-income countries in order to make them comparable to those in more industrialized countries. Bhutta et al 2014 [7] used the Lives Saved Tool (LiST) to conduct an analysis of the potential impacts and costs of such efforts using country-level data. One of the main findings from this analysis was that worldwide, 71\% (1.9 million) of neonatal deaths per year could be averted through 100\% coverage and improved quality of interventions before and during pregnancy, as well as during the intra-partum and post-partum periods. A systematic review of studies from low and middle income countries reported that in 10 out of 19 studies evaluated, there was a significant risk reduction in neonatal mortality among those who delivered at a facility, with a relative risk meta-estimate of 0.71 (95\% CI=0.54, 0.87). [20]. Another systematic review in 2014, however, found no evidence that facility delivery had a significant effect on perinatal mortality (odds ratio (OR) $=1.21,95 \%$ $\mathrm{CI}=0.79-1.84)[21]$.

In addition to health care interventions or service related factors, there are maternal and child biological and socio-demographic factors, as well as household risk factors that have been well documented. For example, male sex is associated with an increased risk, and neonatal mortality tends to cluster within a small subset of mothers and those who have high fertility [22-24]. Examples of socio-demographic factors include the mother's educational status which may affect timely care-seeking for antenatal care or for neonatal infections [11, 25-27]. Another contributor to NM risk is related to unmet need for family planning services which can lead to short inter-pregnancy intervals that confer a high risk of NM [28]. This has also been highlighted by the Lancet Every Newborn Study Group as essential component of improving newborn survival $[29,30]$. In Malawi, demand for family planning needs is met for only $76 \%$ of married women and 53\% of sexually-active unmarried women aged 15 to 49 years [3].

Most evaluations of the effects of health care interventions for reducing NMR in Malawi have been done on a small scale within a few districts, or focusing on only one or two interventions $[1,10,11,31]$. An analysis using the Malawi 2004 DHS showed that those who lived closer to the facility were more likely to deliver there than at home, but facility delivery was not associated with a reduction in the risk of early neonatal mortality [32]. Malawi's national data on summary measures of coverage of neonatal and maternal care interventions have been included in international evaluations of potential impact for these and averaging across countries $[2,7]$. There is a gap in literature that uses a nationally representative data to jointly evaluate the effects of different types of exposures on the risk for NM in Malawi.

The aim of this study was to add to the literature using more recent data from the Malawi 2015/16 DHS. We applied a causal inference approach to individual mother-level data to evaluate the relative effects of two types of risk exposures, namely, lack of access to maternal care and intra-partum services and prior birth history events, on the risk of neonatal mortality. The causal inference approach used here enables us to adjust the attributable risk estimate of each exposure for the effect of its co-exposures, as well as household, maternal and child-specific covariates. The results of this analysis can help guide current efforts to reduce neonatal mortality such as the Every Newborn Action Plan [18] and to help achieve sustainable development goals $[33,34]$.

\section{METHODS}

\section{Data and variables definition}

Data about each participating woman's most recent pregnancy and live birth (within 3 years leading to the survey) were extracted from the Malawi DHS 2015/16. Thus, all information was based on the woman's ability to recall the health care services accessed and their birth history. Various combinations of the following risk exposures were evaluated (Figure 1): having unmet family planning needs for spacing and limiting; not having four or more antenatal care visits (ANC4+), lack of institutional delivery (Ideliv) or skilled birth attendance, having experienced prior neonatal mortality, short (8-24 months vs longer or first pregnancy) birth interval preceding the index birth, first pregnancy vs second or more, two or more pregnancy outcomes within the five years of the survey interview. 


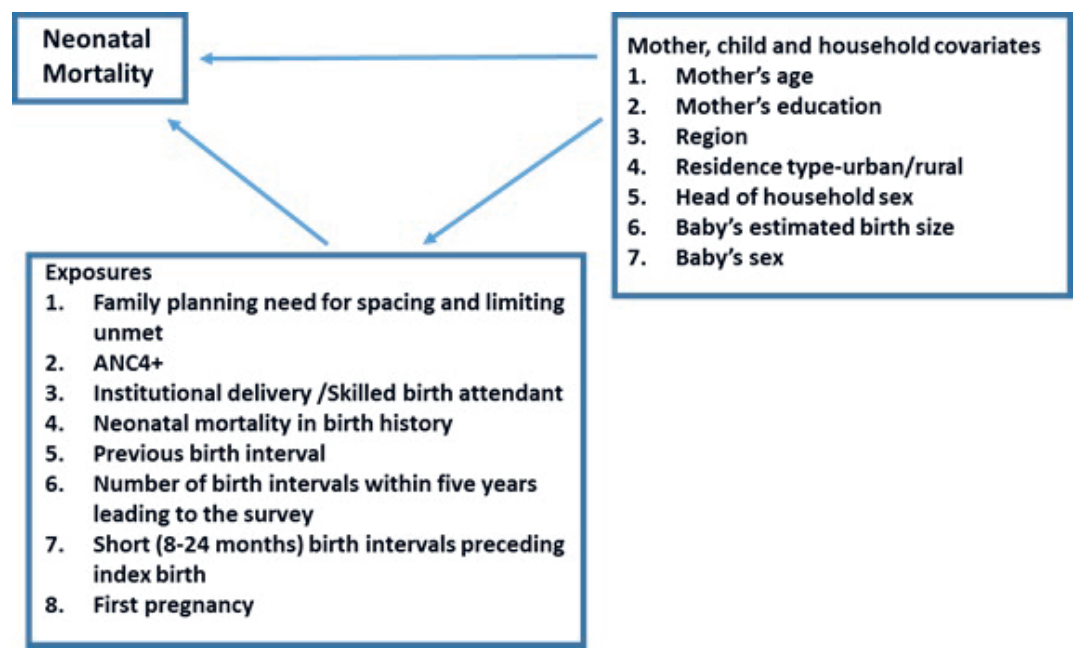

Figure 1. Conceptual diagram for the population intervention models.

Maternal, child and household covariates included the newborn's sex, preceding pregnancy interval, mother's age and education, household socio-economic status, residence type (urban/rural) and region (North, Central and South). The DHS followed a two-stage stratified sampling design where each of the 28 districts in Malawi was stratified into urban or rural, and within those strata, the standard enumeration areas were sampled proportional to size.

\section{Analytical approach}

In this analysis, we fitted population intervention models (PIM) which employ a causal inference approach to determine the relative importance of lack of access to different maternal and newborn-care interventions on the risk of neonatal mortality. Theoretical underpinnings of this approach have been extensively described by Hubbard, van der Laan and Gruber [35-37] and an R implementation of this is in the package multiPIM by Ritter et al (2014) [38]. In order to briefly describe the approach here, we first define the components of our data as follows. $\mathrm{Y}$ is the outcome which is a binary indicator of neonatal death for the most recent live birth; A denotes the exposure so that $\mathrm{A}=0$ if the woman is unexposed (that is, accessed care or has a low risk birth history), and $\mathrm{A}=1$ if exposed; $\mathbf{W}$ is a set of household, mother and child covariates of various types. Since there are multiple exposures in our current study, A is an element of a matrix $\mathbf{A}$ where rows correspond to the individual women and columns correspond to the exposures. Likewise, $\mathbf{W}$ is a matrix of covariates. The causal inference approach assumes that intervention effects have a common model $\mathrm{G}: \mathrm{g}(\mathrm{A} i=\mathrm{O} \mid \mathrm{Wi})$ which gives the predicted probabilities of being in the low risk category $A i=0$ given a vector of covariates Wi. $G$ is widely known as the propensity score and oftentimes, it is simply modeled by a logistic regression for the binary intervention or exposure of interest. A model for the outcome $Y$ is denoted by $Q(A=a, W)$, and this can take on various functional forms depending on the distribution of $\mathrm{Y}$.

Under the causal inference assumptions [38], the PIM approach estimates a target population averaged causal parameter $\varphi$ which is the difference between the overall mean of $Y$ and the mean of the outcome among participants who are unexposed $[\mathrm{A}=0]$, averaged over the covariates:

$$
\varphi=\hat{E}\left[\mathrm{Y}_{0}\right]-\hat{E}[\mathrm{Y}]
$$

In other words, for a $j^{\text {th }}$ exposure $\varphi^{j^{*}}$ is the amount of the outcome that would have been averted if everyone was unexposed to exposure $A^{* *}$. In that sense, the PIM parameter is the reverse of the population attributable risk which is traditionally used in in epidemiology studies.

In the derivation of the potential effects of each exposure, we adjusted for other co-exposures in addition to household, mother and child covariates as well as the DHS sampling weights in the intervention model $\mathrm{g}(\mathrm{O} / \mathrm{W})$. We present the $\varphi$ parameter alongside its estimated standard error and the $P$ associated with the test of the null hypothesis that its true value is 0 . One of the main advantages of following this approach that is worth noting here is the flexibility to specify different candidate parametric and non-parametric models for estimating $\mathrm{g}(\mathrm{O} \mid \mathrm{W})$ and $\mathrm{Q}(\mathrm{O}, \mathrm{W})$. The best among these is selected via $v$-fold cross-validation. 
Table 1. Characteristics of the participants - women and newborns from the most recent live birth within 3 years of the survey

\begin{tabular}{lcc} 
Total & II & $\%$ \\
\hline Region: & 9553 & 100 \\
\hline North & 1667 & 18.17 \\
\hline Central & 3182 & 34.69 \\
\hline South & 4323 & 47.13 \\
\hline Residence type: & & \\
\hline Urban & 1462 & 15.94 \\
\hline Rural & 7710 & 84.06 \\
\hline Mother's age group (years): & & \\
\hline $15-19$ & 1009 & 11 \\
\hline $20-24$ & 2892 & 31.53 \\
\hline $25-29$ & 2056 & 22.42 \\
\hline $30-34$ & 1649 & 17.98 \\
\hline $35-39$ & 1051 & 11.46 \\
\hline $40-49$ & 515 & 5.61 \\
\hline
\end{tabular}

\begin{tabular}{lcc}
\hline Mother's education: & & \\
\hline No education & 1037 & 11.31 \\
\hline Primary & 6129 & 66.82 \\
\hline Secondary & 1841 & 20.07 \\
\hline Higher & 165 & 1.8 \\
\hline Head of household sex: & & \\
\hline Male & 6945 & 75.72 \\
\hline Female & 2227 & 24.28 \\
\hline Household socio-economic status: & & \\
\hline Poorest & 2107 & 22.97 \\
\hline Poorer & 2007 & 21.88 \\
\hline Middle & 1802 & 19.65 \\
\hline Richer & 1672 & 18.23 \\
\hline Richest & 1584 & 17.27 \\
\hline Facility delivery: & \\
\hline No & 596 & 6.5 \\
\hline Yes & 8576 & 93.5 \\
\hline Child sex: & & \\
\hline Male & 4626 & 50.44 \\
\hline Female & 4546 & 49.56 \\
\hline Child's weight estimate based on recall: & \\
\hline Very large & 783 & 8.54 \\
\hline Than average & 2334 & 25.45 \\
\hline Average & 4610 & 50.26 \\
\hline Than average & 1073 & 11.7 \\
\hline Very small & 372 & 4.06 \\
\hline Preceding birth interval (months): & 1906 & 20.78 \\
\hline $8-24$ & 2460 & 26.82 \\
\hline $25-36$ & 2367 & 25.81 \\
\hline $37-50$ & & \\
\hline $51-226$ & & \\
\hline First pregnancy & & \\
\hline & & \\
\hline
\end{tabular}

In Exposure Set B, first pregnancy and birth interval were removed and replaced by having 2 or more pregnancy outcomes within the last 5 years of the survey and this had a population attributable risk of 3 per 1000 live births $(P=0.004)$. In Exposure Set $C$, having previous neonatal mortality had a negligible population attributable risk 0.2 per 1000 live births $(P=0.34)$. In all three models, having unmet family planning needs for spacing or limiting was found to have an attributable risk of $1.2 / 1000$ (Ps=0.08). In sensitivity analyses where birth history was excluded, the population attributable risk of having family planning needs unmet remained the same.
This is referred to as the 'super learner' approach. We estimated our TMLE parameters with logistic regression for the exposure (g) models and a nonparametric recursive partitioning for the outcome $(\mathrm{Q})$ models.

Analysis was carried out with 3 combinations of the risk exposures due to a strong correlation (hence complete confounding) between birth intervals and the number of pregnancy outcomes in the past 5 years, and between institutional delivery and skilled birth attendance; and also because of small sample sizes in the high risk categories of previous neonatal mortality and shortest birth intervals. With small sample sizes, different stratifications led to some categories having probabilities that were completely determined (all 0s or 1s).

\section{RESULTS}

Table 1 lists the characteristics of 9553 women who participated in the DHS survey and had a live birth within 3 years leading to the survey. Table 2 shows the different exposures and the corresponding unadjusted estimates of the risk of neonatal death. The overall neonatal mortality rate was 18.5 per 1000 live births, and this varied by categories (high or low risk) of each of the exposures.

The exposures that had the least proportions of exposed mothers during their most recent pregnancy were ANC4+ visits (50\%), two or more births under 5 in the last 5 years (36\%), first pregnancy (26\%). Institutional delivery / SBA and the shortest birth interval of 18-24 months had the least number of exposed women (Table 3 ). The naive population attributable risk (that is, the difference between the proportion of those who were in the low risk category and had a neonatal death, and the overall NM rate) ranged from 0 to 3 per 1000 live births that could have been protected from the risk of neonatal death if everyone had been unexposed (Table 3).

Table 4 shows the adjusted TMLE estimates of the causal parameters $\varphi^{j}$. The adjusted estimates of the population attributable risk parameter ranged from 0 to 3.9 per 1000 live births that would have potentially been protected from neonatal deaths had everyone been in the low risk category. In the first combination of exposures (Exposure Set A), first pregnancies were associated with the highest-risk of 3.9 per 1000 live births $(P<0.001)$. Having less than 4 ANC visits had the second largest attributable risk of 2.1 per 1000 live births because of the high prevalence of this exposure but this was not statistically significant after adjusting for covariates and co-exposures. Non-institutional delivery and the shortest birth interval (8-24 months) each had a population attributable risk of 1.3 per 1000 live births $\left(P_{S}=0.01\right)$. In a sensitivity analysis where SBA was used instead of institutional delivery, the population attributable risk for non-SBA was 1.6 per 1000 live births $(P=0.005)$. In a sensitivity analysis where first pregnancy was added without the shortest birth interval, the population attributable risk for first pregnancy was 2.9 per 1000 live births $(P=0.02)$. 
Table 2. Exposures and the associated neonatal mortality rates by category

\begin{tabular}{|c|c|c|}
\hline & N & NMR/1000 \\
\hline Total & 9553 & 18.5 \\
\hline \multicolumn{3}{|c|}{ Facility delivery } \\
\hline No & 608 & 41.2 \\
\hline Yes & 8945 & 18.3 \\
\hline \multicolumn{3}{|l|}{ ANC 4+: } \\
\hline No & 4742 & 22.7 \\
\hline Yes & 4811 & 17.1 \\
\hline \multicolumn{3}{|c|}{ Skilled birth attendant: } \\
\hline No & 751 & 40.3 \\
\hline Yes & 8802 & 17.9 \\
\hline \multicolumn{3}{|c|}{ Two + pregnancy outcome in the last 5 years: } \\
\hline No & 6074 & 16.6 \\
\hline Yes & 3479 & 25.6 \\
\hline \multicolumn{3}{|c|}{ Shortest birth interval: } \\
\hline$>24$ months & 8795 & 18.4 \\
\hline $8-24$ months & 758 & 37.2 \\
\hline \multicolumn{3}{|c|}{ First pregnancy: } \\
\hline No & 7078 & 17.8 \\
\hline Yes & 2475 & 25.6 \\
\hline \multicolumn{3}{|c|}{ Previous NNM: } \\
\hline No & 9472 & 19.9 \\
\hline Yes & 81 & 24.1 \\
\hline
\end{tabular}

NMR - neonatal mortality rate, ANC - antenatal care, NNM - neonatal mortality

\section{DISCUSSION}

We have conducted an evaluation of the effect of not accessing some maternal and intra-partum care services, and individual's prior birth history on the risk of NM in Malawi. Lack of institutional delivery or skilled birth attendance, and pregnancy history birth history evaluations at ANC visits have significant roles to play. To our knowledge, these two types of exposures have not been evaluated within the same analysis for their relative effects on the risk of NM in Malawi. Our analysis addresses this existing gap in the literature, and it provides valuable information to help identify interventions that have a potential to change the trajectory of NM if they were scaled up. We note that the significant effect of birth history factors on the risk of NM likely indicates that women who are at an increased risk may not be receiving adequate care. This may be due to the gaps that still exist in the service readiness and quality of implementation of the existing $\mathrm{WHO}$ recommendations for family-planning and antenatal care services [12-19].

Our findings with respect to birth history factors are similar to what has been reported in the literature, which shows an

Table 3. Unadjusted estimates of exposures and associated population attributable risk*

\begin{tabular}{|c|c|c|c|c|c|}
\hline & $\begin{array}{l}\text { Proportion IN THE } \\
\text { EXPosed GROUP }\end{array}$ & $\begin{array}{l}\text { Proportion In the UNEX- } \\
\text { POSEd group WITH NNM }\end{array}$ & $\begin{array}{l}\text { Proportion IN EXPosed } \\
\text { group WITH NNM }\end{array}$ & $\begin{array}{l}\text { NaIVE POPULATION ATTRIB- } \\
\text { UTABLE RISK PROPORTION }\end{array}$ & $\begin{array}{l}\text { NaIVE POPULATION ATTRIBUT- } \\
\text { abie RISK ratE(PER 1000) }\end{array}$ \\
\hline Institutional delivery & 0.064 & 0.0172 & 0.0378 & -0.0013 & -1.3 \\
\hline ANC4+ & 0.496 & 0.0168 & 0.0202 & -0.0017 & -1.7 \\
\hline SBA & 0.079 & 0.0169 & 0.0373 & -0.0016 & -1.6 \\
\hline Family planning need unmet & 0.166 & 0.0173 & 0.0245 & -0.0012 & -1.2 \\
\hline Two or more births under- 5 & 0.364 & 0.0158 & 0.0233 & -0.0027 & -2.7 \\
\hline Shortest ( $<24$ months) birth interval & 0.079 & 0.0175 & 0.0303 & -0.001 & -1.0 \\
\hline First pregnancy & 0.259 & 0.0165 & 0.0242 & -0.002 & -2.0 \\
\hline Previous NNM & 0.009 & 0.0184 & 0.0370 & -0.0001 & -0.1 \\
\hline
\end{tabular}

NMR - neonatal mortality rate, ANC - antenatal care, NNM - neonatal mortality, SBA - skilled birth attendance

*Attributable risk estimates expressed as proportions as well as deaths per 1000 live births potentially averted. Proportions are rounded to 3 decimal places.

Table 4. Attributable risk parameter estimates: expressed as deaths per 1000 live births that could have potentially been averted had everybody been in the unexposed category

\begin{tabular}{|c|c|c|c|c|}
\hline \multicolumn{5}{|l|}{ Exposure Set A } \\
\hline Exposure & Parameter estimate & Standard error & Test statistic & $P$-value \\
\hline Institutional delivery & -1.3 & 0.5 & 2.550 & 0.011 \\
\hline ANC4+ & -2.1 & 1.4 & 1.514 & 0.130 \\
\hline Family planning need unmet & -1.2 & 0.7 & 1.760 & 0.078 \\
\hline Shortest ( $<24$ months) birth interval & -1.3 & 0.5 & 2.601 & 0.009 \\
\hline First pregnancy & -3.9 & 1.1 & 3.411 & 0.001 \\
\hline \multicolumn{5}{|l|}{ Exposure Set B } \\
\hline Exposure & Parameter estimate & Standard error & Test statistic & $P$-value \\
\hline Institutional delivery & -1.3 & 0.5 & 2.506 & 0.012 \\
\hline ANC4+ & -1.9 & 1.4 & 1.376 & 0.169 \\
\hline Family planning need unmet & -1.2 & 0.7 & 1.721 & 0.085 \\
\hline Two or more births under- 5 & -3.2 & 1.1 & 2.855 & 0.004 \\
\hline \multicolumn{5}{|l|}{ Exposure Set C } \\
\hline Exposure & Parameter estimate & Standard error & Test statistic & $P$-value \\
\hline Institutional delivery & -1.3 & 0.5 & 2.595 & 0.001 \\
\hline ANC4+ & -2.1 & 1.4 & 1.495 & 0.135 \\
\hline Family planning need unmet & -1.2 & 0.7 & 1.787 & 0.074 \\
\hline Previous NNM & -0.2 & 0.2 & 0.958 & 0.338 \\
\hline
\end{tabular}

$\mathrm{NNM}$ - neonatal mortality, ANC4+ - four or more antenatal care visits 
elevated risk among first time mothers, and for births preceded by short inter-pregnancy / inter-birth intervals [39-46]. Furthermore, the finding of an elevated risk for high fertility mothers is similar to that of Kozuki et al (2013) [28] who found that among mothers with high fertility, there was an elevated risk of NM for all children irrespective of birth order, after adjusting for socioeconomic and reproductive health factors. This, they noted, suggest some residual confounders that explain a specific type of risk suffered by children born to high fertility mothers. One could also argue that this may be reverse causality in a sense that mothers who experience neonatal deaths may be more likely to try and have more children. Our findings with respect to institutional delivery contradict a finding from a study using the Malawi 2004 DHS data [32] in which facility delivery was not shown to be associated with a reduced risk on NM.

The population attributable risks associated with lack of access to institutional delivery/skilled birth attendance and birth history factors, though statistically significant, are relatively small compared to the overall NMR, and this is further evidence that there are some residual effects of unmeasured covariates such as maternal biological factors or household factors as well as quality of service at facilities which lead to clustering on NM within a small subset of mothers [23]. Furthermore, care-seeking for early neonatal illness is often delayed or not practiced in some low-income settings due to various social and economic factors $[6,11,25,47,48]$. Hence there is still a need for programs to identify and target high risk mothers who have had adverse events in the past or who may be less likely to seek care for neonatal illness. We also note that the ability to identify and address the needs of high risk mothers is highly dependent on adequate service quality and facility readiness. The most recent literature indicates that this is still lacking in Malawi [12]. Our future work will involve an assessment of service readiness for ANC and obstetric care from the perspective of the mother given at exit interviews.

The multi parameter intervention models approach used here offers an efficient way to apply machine learning algorithms to evaluate the marginal effects of the exposures, adjusting for co-exposures and for baseline covariates. The availability of the $\mathrm{R}$ implementation of this approach offers researchers a vehicle to apply this in exploratory analysis where there could potentially be large numbers of interventions and covariates. The causal parameter has an interpretation akin to the widely used population attributable risk, and it can be derived using the traditional semi-parametric and non-parametric models as the foundation for estimating the propensity score (g) models and the outcome (Q) models.

One of the limitations of our study is that our data on access to different interventions and birth history services is dependent on the participating mother's ability to recall the events. We limited this by only evaluating data from the most recent births within 3 years of the survey. Another potential problem is that there may be misclassification of neonatal deaths and stillbirths [49]. The multiPIM package does not yet support methods that include missing values in some of the predictors. The interventions related to vaccinations and medications received during pregnancy were also considered but they had large numbers of missing values which made it difficult to conduct reliable estimates.

\section{CONCLUSIONS}

Our analysis addresses the gap in the literature on evaluating the effect of these exposures in Malawi, and it helps inform programs and current efforts such as the Every Newborn Action 2020 Plan. It shows that increasing access to maternal care interventions has an important role to play in changing the trajectory of neonatal mortality. Birth history factors play an important role on the risk of NM and we hypothesis that women who are at an increased risk may not be receiving adequate care. Recent studies indicate that gaps that still exist in the service readiness and quality of implementations of the existing WHO-recommendations for family planning and antenatal care services, as indicated by recent studies.

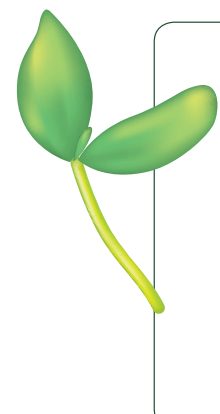

Acknowledgements: The data used in this study were collected by the DHS Program with funding from the USAID https://dhsprogram.com/

Ethics approval: We used publically available de-identified DHS data in accordance to the program's usage policies. Funding: No funding was available for this research.

Authorship contributions: BASN conceived the idea, conducted all analyses and drafted the manuscript. EC provided guidance on the relevant exposures and covariates to evaluate and contributed to manuscript writing.

Competing interests: The authors have completed the Unified Competing Interest form at www.icmje.org/coi_disclosure.pdf (available on request from the corresponding author) and declare no competing interests. 
1 Doherty T, Zembe W, Ngandu N, Kinney M, Manda S, Besada D, et al. Assessment of Malawi's success in child mortality reduction through the lens of the Catalytic Initiative Integrated Health Systems Strengthening programme: Retrospective evaluation. J Glob Health. 2015;5:020412. Medline:26649176 doi:10.7189/jogh.05.020412

2 Kanyuka M, Ndawala J, Mleme T, Chisesa L, Makwemba M, Amouzou A, et al. Malawi and Millennium Development Goal 4: a Countdown to 2015 country case study. Lancet Glob Health. 2016;4:e201-14. Medline:26805586 doi:10.1016/ S2214-109X(15)00294-6

3 MDHS. Demographic and Health Survey Program. 2015. Available: http://dhsprogram.com/what-we-do/survey/survey-display-483.cfm. Accessed: 1 July 2018.

4 Moise IK, Kalipeni E, Jusrut P, Iwelunmor JI. Assessing the reduction in infant mortality rates in Malawi over the 19902010 decades. Glob Public Health. 2017;12:757-79. Medline:27696987 doi:10.1080/17441692.2016.1239268

5 World Bank. Country Indicators. 2017. Available: http://data.worldbank.org/indicator/SP.POP.TOTL/countries/MW?display=graph. Accessed: 1 July 2018.

6 Zimba E, Kinney MV, Kachale F, Waltensperger KZ, Blencowe H, Colbourn T, et al. Newborn survival in Malawi: a decade of change and future implications. Health Policy Plan. 2012;27 Suppl 3:iii88-103. Medline:22692419 doi:10.1093/ heapol/czs043

7 Bhutta ZA, Das JK, Bahl R, Lawn JE, Salam RA, Paul VK, et al. Can available interventions end preventable deaths in mothers, newborn babies, and stillbirths, and at what cost? Lancet. 2014;384:347-70. Medline:24853604 doi:10.1016/ S0140-6736(14)60792-3

8 Fottrell E. David Osrin, Glyn Alcock, Kishwar Azad, Ujwala Bapat, James Beard, et al. Cause-specific neonatal mortality: analysis of 3772 neonatal deaths in Nepal, Bangladesh, Malawi and India. Arch Dis Child Fetal Neonatal Ed. 2015;100:F439-47.

9 MICS-UNICEF. Malawi MICS 2014. 2014. Available: https://mics-surveys-prod.s3.amazonaws.com/MICS5/Eastern\%20 and\%20Southern\%20Africa/Malawi/2013-2014/Final/Malawi\%202013-14\%20MICS\%20\%28MDG\%20Endline\%20 Survey\%29_English.pdf. Accessed: 1 July 2018.

10 Atuoye KN, Amoyaw JA, Kuuire VZ, Kangmennaang J, Boamah SA, Vercillo S, et al. Utilisation of skilled birth attendants over time in Nigeria and Malawi. Glob Public Health. 2017;12:728-43. Medline:28441927 doi:10.1080/174416 92.2017 .1315441

11 Koffi AK, Mleme T, Nsona H, Banda B, Amouzou A, Kalter HD. Social autopsy of neonatal mortality suggests needed improvements in maternal and neonatal interventions in Balaka and Salima districts of Malawi. J Glob Health. 2015;5:010416. Medline:27698997

12 Leslie HH, Fink G, Nsona H, Kruk ME. Obstetric facility quality and newborn mortality in Malawi: A cross-sectional study. PLoS Med. 2016;13:e1002151. Medline:27755547 doi:10.1371/journal.pmed.1002151

13 Kanyangarara M, Chou VB, Creanga AA, Walker N. Linking household and health facility surveys to assess obstetric service availability, readiness and coverage: evidence from 17 low- and middle-income countries. J Glob Health. 2018;8:010603. Medline:29862026 doi:10.7189/jogh.08.010603

14 Kanyangarara M, Munos MK, Walker N. Quality of antenatal care service provision in health facilities across sub-Saharan Africa: Evidence from nationally representative health facility assessments. J Glob Health. 2017;7:021101. Medline:29163936 doi:10.7189/jogh.07.021101

15 World Health Organization. A guide to family planning for community health workers and their clients. Geneva: World Health Organization; 2012.

16 World Health Organization. Service availability and readiness assessment (SARA): an annual monitoring system for service delivery. Geneva: World Health Organization; 2013.

17 World Health Organization. WHO recommendations on antenatal care for a positive pregnant experience. Geneva: World Health Organization; 2016.

18 World Health Organization. Every Newborn Action Plan. 2017. Available: http://www.who.int/maternal_child_adolescent/newborns/every-newborn/en/. Accessed: 1 July 2018.

19 World Health Organization-USAID. The Service Provision Assessment (SPA). USAID: Rockville, MD: WHO-USAID; 2012.

20 Tura G, Fantahun M, Worku A. The effect of health facility delivery on neonatal mortality: systematic review and meta-analysis. BMC Pregnancy Childbirth. 2013;13:18. Medline:23339515 doi:10.1186/1471-2393-13-18

21 Chinkhumba J, De Allegri M, Muula AS, Robberstad B. Maternal and perinatal mortality by place of delivery in sub-Saharan Africa: a meta-analysis of population-based cohort studies. BMC Public Health. 2014;14:1014. Medline:25263746 doi:10.1186/1471-2458-14-1014

22 Kozuki N, Oseni L, Mtimuni A, Sethi R, Rashidi T, Kachale F, et al. Health facility service availability and readiness for intrapartum and immediate postpartum care in Malawi: A cross-sectional survey. PLoS One. 2017;12:e0172492. Medline:28301484 doi:10.1371/journal.pone.0172492

23 Nonyane BA, Williams EK, Blauvelt C, Shah MR, Darmstadt GL, Moulton L, et al. Clustering of neonatal deaths in Bangladesh: results from the Projahnmo studies. Paediatr Perinat Epidemiol. 2013;27:165-71. Medline:23374061 doi:10.1111/ ppe. 12032

24 Omariba WR, Rajulton F, Beaujot R. Correlated mortality risks of siblings in Kenya: the role of state dependence. Demogr Res. 2008;18:311-36. doi:10.4054/DemRes.2008.18.11

25 Nonyane BA, Kazmi N, Koffi AK, Begum N, Ahmed S, Baqui AH, et al. Factors associated with delay in care-seeking for fatal neonatal illness in the Sylhet district of Bangladesh: results from a verbal and social autopsy study. J Glob Health. 2016;6:010605. Medline:27350876 doi:10.7189/jogh.06.010605 
26 Noordam AC, Sharkey AB, Hinssen P, Dinant G, Cals JW. Association between caregivers' knowledge and care seeking behaviour for children with symptoms of pneumonia in six sub-Saharan African countries. BMC Health Serv Res. 2017;17:107. Medline:28153011 doi:10.1186/s12913-017-2060-3

27 Sandberg J, Odberg Pettersson K, Asp G, Kabakyenga J, Agardh A. Inadequate knowledge of neonatal danger signs among recently delivered women in southwestern rural Uganda: a community survey. PLoS One. 2014;9:e97253. Medline:24824364 doi:10.1371/journal.pone.0097253

28 Kozuki N, Walker N. Exploring the association between short/long preceding birth intervals and child mortality: using reference birth interval children of the same mother as comparison. BMC Public Health. 2013;13 Suppl 3:S6. Medline:24564713 doi:10.1186/1471-2458-13-S3-S6

29 Starrs AM. Survival convergence: bringing maternal and newborn health together for 2015 and beyond. Lancet. 2014;384:211-3. Medline:24853594 doi:10.1016/S0140-6736(14)60838-2

30 Darmstadt GL, Kinney MV, Chopra M, Cousens S, Kak L, Paul VK, et al. Who has been caring for the baby? Lancet. 2014;384:174-88. Medline:24853603 doi:10.1016/S0140-6736(14)60458-X

31 Kuuire VZ, Kangmennaang J, Atuoye KN, Antabe R, Boamah SA, Vercillo S, et al. Timing and utilisation of antenatal care service in Nigeria and Malawi. Glob Public Health. 2017;12:711-27. Medline:28441926 doi:10.1080/17441692. 2017.1316413

32 Lohela TJ, Campbell OMR, Gabrysch S. Distance to care, facility delivery and early neonatal mortality in Malawi and Zambia. PLoS One. 2012;7:e52110. Medline:23300599 doi:10.1371/journal.pone.0052110

33 Countdown2030. Countdown to 2030: Maternal, Newborn and Child Survival. 2017. Available: http://countdown2030. org/ Accessed: 1 July 2018

34 Victora C, Requejo J, Boerma T, Amouzou A, Bhutta ZA, Black RE, et al. Countdown to 2030 for reproductive, maternal, newborn, child, and adolescent health and nutrition. Lancet Glob Health. 2016;4:e775-6. Medline:27650656 doi:10.1016/S2214-109X(16)30204-2

35 Hubbard AE, Laan MJ. Population intervention models in causal inference. Biometrika. 2008;95:35-47. Medline:18629347 doi:10.1093/biomet/asm097

36 van der Laan MJ. Statistical inference for variable importance. Int J Biostat. 2006;2:2. doi:10.2202/1557-4679.1008

37 van der Laan MJ, Gruber S. Targeted minimum loss based estimation of causal effects of multiple time point interventions. Int J Biostat. 2012;8:1. Medline:22611591 doi:10.1515/1557-4679.1370

38 Ritter SJ, Jewell NP, Hubbard AE. R Package multiPIM: A causal Inference Approach to Variable Importance Analysis. J Stat Softw. 2014;57:1-29. doi:10.18637/jss.v057.i08

39 Fotso JC, Cleland J, Mberu B, Mutua M, Elungata P. Birth spacing and child mortality: an analysis of prospective data from the Nairobi urban health and demographic surveillance system. J Biosoc Sci. 2013;45:779-98. Medline:22958417 doi:10.1017/S0021932012000570

40 Conde-Agudelo A, Rosas-Bermudez A, Kafury-Goeta AC. Birth spacing and risk of adverse perinatal outcomes: a meta-analysis. JAMA. 2006;295:1809-23. Medline:16622143 doi:10.1001/jama.295.15.1809

41 Zhu BP. Effect of interpregnancy interval on birth outcomes: findings from three recent US studies. Int J Gynaecol Obstet. 2005;89 Suppl 1:S25-33. Medline:15820365 doi:10.1016/j.ijgo.2004.08.002

42 Conde-Agudelo A, Belizán JM, Breman R, Brockman SC, Rosas-Bermudez A. Effect of the interpregnancy interval after an abortion on maternal and perinatal health in Latin America. Int J Gynaecol Obstet. 2005;89 Suppl 1:S34-40. Medline:15820366 doi:10.1016/j.ijgo.2004.08.003

43 Conde-Agudelo A, Belizán JM, Norton MH, Rosas-Bermúdez A. Effect of the interpregnancy interval on perinatal outcomes in Latin America. Obstet Gynecol. 2005;106:359-66. Medline:16055588 doi:10.1097/01.AOG.0000171118.79529.a3

44 Rutstein SO. Effects of preceding birth intervals on neonatal, infant and under-five years mortality and nutritional status in developing countries: evidence from the demographic and health surveys. Int J Gynaecol Obstet. 2005;89 Suppl 1:S7-24. Medline:15820369 doi:10.1016/j.ijgo.2004.11.012

45 DaVanzo J, Hale L, Razzaque A, Rahman M. The effects of pregnancy spacing on infant and child mortality in Matlab, Bangladesh: how they vary by the type of pregnancy outcome that began the interval. Popul Stud (Camb). 2008;62:13154. Medline:18587691 doi:10.1080/00324720802022089

46 Norton M, Shelton JD. Stillbirth and healthy timing and spacing of pregnancy. Lancet. 2011;378:876, author reply 8767. Medline:21890046 doi:10.1016/S0140-6736(11)61411-6

47 Owais A, Faruque AS, Das SK, Ahmed S, Rahman S, Stein AD. Maternal and antenatal risk factors for stillbirths and neonatal mortality in rural Bangladesh: a case-control study. PLoS One. 2013;8:e80164. Medline:24244638 doi:10.1371/ journal.pone.0080164

48 Waiswa P, Kallander K, Peterson S, Tomson G, Pariyo GW. Using the three delays model to understand why newborn babies die in eastern Uganda. Trop Med Int Health. 2010;15:964-72. Medline:20636527 doi:10.1111/j.13653156.2010.02557.x

49 Liu L, Kalter HD, Chu Y, Kazmi N, Koffi AK, Amouzou A, et al. Understanding misclassification between neonatal deaths and stillbirths: empirical evidence from Malawi. PLoS One. 2016;11:e0168743. Medline:28030594 doi:10.1371/journal.pone.0168743 